\title{
The Various Inclinations to the Questions of Modality and Discourse
}

\author{
Fidan Salimova ${ }^{1}$ \\ ${ }^{1}$ The Institute of Linguistic named after I.Nasimi, Azerbaijan National Academy of Sciences, Baku, Azerbaijan \\ Correspondence: Fidan Salimova, The Institute of Linguistic named after I. Nasimi, Azerbaijan National \\ Academy of Sciences, Baku, Azerbaijan. E-mail: fidan_adu@mail.ru
}

Received: January 20, 2015 Accepted: February 19, 2015 Online Published: March 29, 2015

doi:10.5539/ijel.v5n2p165

URL: http://dx.doi.org/10.5539/ijel.v5n2p165

\begin{abstract}
Although the notion of discourse has recently been appeared in linguistics, currently it is widely used in many disciplines. Presently, under the name of discourse text is implied together with the context in the broadest sense, it also includes the social context as well. The attitude of the speaker to the reality is reflected in discourse. Thus, modality is considered to be a key component of discourse.
\end{abstract}

Keywords: discourse, modality, text, verbal, non-verbal, subjective, objective, irreal/unreal

\section{Introduction}

We know that discourse has specially been taken place among many scientific spheres at the present-day though the term of discourse is younger among the linguistic ideas, and the term is often heard nowadays.

We'd like to generalize the most various signs and inclinations in discourse.

1) When we say "discourse" we mean texts from the most different aspects. O. I. Moskalskaya writes about text "it (text) consists of one or more sentences, and according to the speakers' thought they are the sayings that have complete meanings, but a narrative, a novel, newspaper and journal articles, scientific monographs, various documents and etc. are considered to be speech facts as well (Moskalskaya, 1981).

2) Discourse is also connected with speech. Z. Harris considers that discourse is a larger part of text than a sentence. The French scientist Emili Benvenist considers discourse as "the speech of speakers" and notes that sentences are the expressions of speakers.

3) As discourse differs from text which has a formal grammatical structure, it is meant to be the text of activated one. Generally, discourse is a complete result of a communicative act.

4) Discourse is coherent text.

5) Discourse is a set of connection of speech's acts. Clearly, the acceptance of a sentence demands some preparation level on the listener (reader).

A. Mammadov concretizes the problem a bit more and says "If we compare discourse and text, discourse is accepted as a speech act that acts. It gets some meaning through the context", and the author again states that "discourse is considered as a connected speech part." (Mamedov, 2008)

\section{Verbal and Non-verbal Speech}

It is impossible to deliver all sayings that said by any subject by means of words. In the verbal speech the elements with out of speech plays an important role and in a number of situations even plays a leading role, but in the written texts these elements stay in out of the text.

The communication (verbal or written) is not built up only by the help of words. We would like to draw your attention to the fact that in the written speech some senses such as feeling, excitement etc. are not delivered only by the help of grammar rules and norms as well as they can be delivered by means of the words which do not carry lexical meanings such as functional words, the deliberately inverted order of words, phonetic means etc. In verbal speech most verbal elements play a very important role in speech for example, gesture, mimicry, some ways of speech that help to bridge the communication etc. V. V. Bogdanov thinks that none verbal means carry more pragmatic nature that the semantic ones (Bogdanov, 1987). The silence acts and actionable components are considered to be the means of none verbal communication. The first ones are shown with the dots in the written speech. It's true that these writing means cannot express all the shades of "nonsense", but can give some 
information about them. However, delivering the second ones is almost mysterious. Furthermore, in the literary text an author can give the imagination about the motions relating with the context.

When we talk about the none-verbal speech components, we should pay attention to the one fact. The meaning and the adoption of them are very different in various nations. The pause of silence, the movements of hands, face mimicry are very special in each nation, and there are a number of situations that can express opposite meaning.

Shortly, we can state that the verbal and non-verbal (averbal) components can be joined in the structure of communication. These two components, the text and context (to say in comprehensive form averbal and social surrounds) together create discourse. As there is not any complete definiteness in the explanation of discourse conception, it is too difficult to definite the components that create them.

The meaning of text in discourse reflects the real relations of speakers and speakers to speakers also the same relations are realized in two ways. The same relation "sentences are the expression of speakers" is realized with language meanings and non-verbal means. In any cases the relations connect with modality and in their delivery the modal verbs; word-combinations take place according to grammatical language meanings. If we consider that for example, the modal verbs and the modality do not take the same place in all languages and do not give the same meanings, so the mutual investigation of the same problem in different languages can be clarified not only with modal conception but the discourse conception that takes an important place in speech and would be progress in their researching.

Though the conception of modality has been used in our language for a long time, there is not any complete explanation in their meaning capacity, surroundings and for their grammar function between the languages units. For our consideration the main reason is the modality conception's place in the language, and its function is not only in the level of grammar and carries out in other side. Because some specialists use the modality in limited situations and identify them with the modal verbs, despite some specialists widely approach to the conception and look them through the real relations of talkers and speakers.

\section{Modality}

All our sentences are mainly connected with the spaciousness of modality.

According to the limited approach the language's modality reduces the intellectual modality level of discretion; the formal intellectual differences as possibility, necessity and reality meanings are limited (G. V. Kolshanskiy, S. İ. Nebikova, V. Z. Panfilov, V. N. Bondarenko, M. K. Sabaneeva, T. İ. Desherieva, İ. İ. Grebenkina). All these approaches are not supported by linguists, because "the modal qualification that intellectually adopted in expressions cannot be oriented for linguistic conception of modality it is not used from the semantic diapason realizing in natural language of objectivity means of narration, also they even cannot express the full meaning connected with the exactness of accuracy level of simply sayings" (Lyapon, 1971).

Wide extensive approach takes more place in linguistic. According to the same approach, to the meaning capacity of modality includes not only possibility, necessity and the meanings of reality, but reality/unreality, authentic, probability, desire, as well as the approval/denial, emotionality, authorization, evaluation, bringing to mind, desire communication, pragmatics of context, question/answer meanings. But these kinds of interpretations have their flaws. Thus, if the amount of content in a wide range of structural modality would remove, it could turn into something abstract linguistic categories, so it rightly researchers continue to seek more effective research orientation. One of these points and perhaps, in our opinion, the most logical one is the functional approach, which ultimately is based on "relationship".

Recently, much attention has been paid to the study of modality viewpoint of functional approach (A. V. Bondarko, G. A. Zolotova, E. Belyaeva, S. S. Vaulina, S. A. Gekhtler, N. O. Pavlovskaya, T. V. Shmeleva, Z. L. Novojenova etc.). In this regard, the modality is assessed as functional-semantic category that organizes wide expression means and methods also for its multi-content terms and for the principles of wide range of areas.

Among them the scope of modality content and with the functional sense hierarchy of sentences two aspects, it means, it defined with its nominal (propositional) and communicative (pragmatic) aspects as a wide semantic category, but for our opinion the same position of researchers seems more reasonable (S. S. Vaulin, L. V. Kolobkova, I. O. Kuksa, I. R. Fedorova, O. L. Kochetkova etc.).

Of course, in each written and spoken sentences (regardless of size) in these or in any other levels there are some relations that substantially attitude. This means that there should be any modality in each sentence. Ghazanfar Kazımov comments on the same issue and says that "information can be given in each sentence about objective world or situation and it gives its own opinion to the thought of speakers as well. It means, the same sentence 
conveys both communicative and expressive function. One of constructive signs of the sentence as it acts as a speech is the universal semantic category of modality. The same category plays an important role in formalization of communicative perspectives. The emotional-expressive function of the sentence creates the modality" The scientist distinguishesmodal words from the important expression meanings of modality and adds the constructions that are called as "rumours" there, separately shows the grammatical-morphological meanings of modality and says that even "with the support of intonation in any of a sentences, it is possible to use modal types instead of the sentence is in predicate form."

It is considered that modal words cannot be concerned as the main parts of speech or structural parts of speech.

We should focus on the fact that scientists pay special attention to the modal words as viewpoint of imagination of modality categories. If we speak about this character of modal words, we need to mention the special services of A. A. Potebnya, the Russian scientist. He carried out some facts in the creation of grammatical trainings about the sentences. He proved that modal words have been created by rumours and can stress their independent places among the parts of speech. The same conception found its further development in the works of D. N. Ovsyaniko-Kulikovski and A. P. Peshkovski. The mentioned specialists have distinguished the following signs in modal words:

- The close connection of many modal words with the adverbial modifier of manner and quality-defining, the junction of adverbs that have perform the function of modal words;

- A large number of modal particles;

- Modal words' and particles' functions' identification with the verb forms' functions;

- The functional proximity of rumours and modal words and particles.

V. V. Vinogradovone of the Russian linguistics reviewed the modality as a semantic category. He considered the modality as the category of a sentence. "Each sentence has the constructive sign of a modal meaning, it means that there are constructive attitudes showing real relations." (Vinogradov, 1975)

He considered that for determination the structure of a sentence and its type and diversity, it is important to clarify the category of modality. He pointed out that "...the content of category of modality and its detection forms of historically variable. In different language systems the semantic category of modality conveys the lexical-grammatical characterizes. Firstly, O. S. Akhmanova explains the term of modality as the category in "Linguistic terms dictionary". According to the same dictionary, modality is "the attitude of content to the sentences of speakers, the speakers attitude to the reality (given's relation to their realization) is the meaningful conception category, and expresses the different grammatical and lexical forms, for example, verbal forms, modal verbs and etc." (Akhmanova, 1969) We can observe the followings in the same definition:

- Relation of this category to the understanding sphere;

- Semantics: the attitude of speakers to the content of the sentences and the attitude of sentences' content to the attitude of reality;

- The expression means of the category of modality.

Here we can see the distribution of the category of modality: a hypothetical (hypocritical) modality-the presentation of sayings as the probability; verb (verbal) modality-modality denominating with verbs; irreal (unreal) modality - the content is presented as impossible, unreal; denied (negative) modality-which the sentences' content is presented as unsuitable.

N. Y. Svedova for the large number of all groups of subjective modal meanings differentiated from the initial and general opposition: evaluating-characterizing and directly evaluating-differentiating. Thus, the evaluation is considered as the essence of subjective modality (Russian Grammar, 1980). I. R. Galperin also believes that, "the evaluation of facts' imagination is one of main signs of modality" (Galperin, 1981).

The modality in linguistic encyclopaedic dictionary is called as "the functional-semantic category of expression of different types of relations of sentences' classification and the sentences' attitude to the realities" (LED, 1990). As we see, this definition does not differ much from the previous one. V. N. Bondarenko also divides the modality into two sides: objectives ones and subjective ones. According to the above mentioned facts we can conclude that modality is objective and subjective.

According to V. N. Bondarenko's conception modality has been explained as a group of functional-semantic areas that are differentiated from modal meanings subsystem on different aspects' features.

N. S. Valgina shows the same position and considers that modality is the evaluation of attitude of speakers to the 
reality of sentences.

The meta-referent plan of the text is used in the linguistics literature, and it included into more common category of modality. According to L. M. Maydanova's researches the meta-referent "is conditioned to be by the fact of any text or any other form of communication in this situation - first of all, the author and the recipient of the social role, directly or indirectly go into communication, communication reflects the character of the quantity and quality of the parties" (Maidanova, 1987). T. V. Matveyeva includes tonality and rational evaluation to the subjective-modal categories. When T. V. Matveyeva mentions about the tonality, she means the psychological orientation of the author of the text and their text categories.

Following her V. N. Teliya notes that the tonality sphere conveys the psychological self-managing and because of emotional contagion effect of text addressee is very influential. Here should be noted that T. V. Matveyeva practically identifies the modality and the tonality. Speaking about the evaluation peculiarities of the text, T. V. Matveyeva differentiates the rational evaluation and in the newspaper's text distinguishes the availability of evaluation methods.

Y. A. Arbuzova's conception also seems interesting. She analyses the pragmatic peculiarities of connotation in the arrangement of the sentence and shows that the pragmatic connotation of the words, words junction, sentences, another part of the text or content, objective lexical meaning of language sources seem the base of information receivers in different contexts because of directly expressing context (Vinogrodov, 1965).

N. S. Petrunicheva looked through the connotation as the expression means of subjective modality. If the connotation is included to the semantic "branded" lexeme's composition, we can talk about the connotative theme. Though according to N. S. Petrunicheva if the connotation appears as the result of expression in the text of lexemes, in this case we can talk about the connotative theme. "Subjective modality finds its expressions by the receivers during its creational process; the textual connotation's code should be open during the perception" (Petrunicheva, 1990). It is impossible unanimously to agree with the same thoughts, because subjective modality is almost in the textual category.

Two types of modal meaning differentiated in the following section: (1) objective modal meaning that includes the received information to this or other plans of realities, and (2) subjective modal (facultative) meaning, it means, it is the expression of talkers' received meanings to attitude. "To the widely composition of subjective-modal meanings includes the strengthening (stress), expressive evaluation, to be sure or unsure (definite-indefinite), the adopting or not adopting (agreeing or not agreeing) and etc."

Thus, including the subjective meaning of modality to the theory of common modality has an important movement in notifying the transformation from the investigation into text paradigms of modality category in the sentence paradigms.

As it seems from the above mentioned sentence, a conception and a language situation has multi-meanings. The conception of modality is named as "in this or in other form — grammatical, lexis, intonation — joining different situations with the signs of attitude of sentences or speakers' to the realities" (Russian Grammar, 1980). In this term the maintenance of modality conception is clarified more clearly: it is the expression of attitude of talkers to receivers' or receivers' to realities. N. J. Shvedova, the Russian linguist distinguished from less four kinds of situations about the modality:

1) Reality-irreality meaning — the reality is noted with the syntactic indicative —with the present, future and past tenses, but irreality with irreal forms - reserve, conditional, optative, imperative important forms.

2) Subjective modal meaning, it means the attitude of speakers to receivers.

3) Possibility, wish, importance, urgency, compulsory confrontation, preparations' words — verbs, adjectives and predicates are included with their lexical meaning to the modality.

4) The meanings of positive, negative and interrogative words (Russian Grammar, 1980)

We need to note that there are not any definite thoughts of unite among the researches about the functions of modality in the objective and subjective types in the status yet. Even many scientists prove the dialectic relations among the same categories, there are sharply differences between the objective and subjective categories. As Y. V. Miloserdeva says “According to a concrete person's thought there exist the subjective category in their brain from the beginning, it means first of all is appears from the personnel thoughts. But in the speaking processes these subjective meanings must be translated into the forms of system." (Miloserdova, 1991)

Many researchers think that the formal separations of "objective" and "subjective" conceptions for some reasons are conditional (or relative). 
The objective modality expresses the attitude of sentences to the realities in the real/unreal plan. The same type of objective modality is grammatical and represented with putting against the syntactic unreal forms (particle, optative, conditional, imperative, branching) of syntactical predicate form. The objective modality is an absolute sign and formalizes the predicative (sentence) unit.

The predicate form category is characterized with the tense but not in all unreal forms. The objective modal meanings is observed in the grammatical paradigm of the sentences and is shown in predicate form, therefore some scientists call the objective modality as the initial modality.

Subjective modality, it means the attitude of speakers to sentences but it is not an absolute attitude. It creates the second modal line. Its semantic amount is wider than the semantic amount of objective modality. The meaning of content of subjective modality is not unit and demands the systemizing. We should note that in the subjective modality category has collected the anthropocentric peculiarities of the language and it appears during putting the conceptual beginning against the neutral informative background.

The main purpose of subjective modality is characterizing the information subject and expressing its cognitive view of the world.

Many scientists consider that generally, for each sentence the subjective modality is very important. A sentence is impossible without any subjective modality (Totsueva, 1975).

"Subjective modality-is the attitude of sentences to the information. The expressive value to the subjective modality, expresses the absolute or hesitating attitude of speakers, believing-unbelieving, agreeing-not agreeing with speakers thought and etc. For example, there is no doubt, I will write you a letter-(for the word of no doubt) here the subjective modality is put to the objective one (I will write you a letter)." (Kazimov)

However, not every scientists support the separation of modality into subjective and objective parts. For example, modality "the attitude type of sentences to realities" has been noted and the forms of the verb: predicate, imperative and conditional-completely identified (Rudnev, 1997). A. V. Bondarko adds the superior signs (reality/unreality attitude) to the "modality" conception, and also adds the following meaning types of main modality:

- Urgency/potentiality (branching, necessary, hypothetic and etc.);

- Evaluation of exactness;

- The communicative delivery of sentences;

- $\quad$ The evidence (telling/not telling).

According to A. V. Bondarko, the evaluation is partly close with the modality semantics, and it is necessary to look through them as the special semantic - pragmatic zone (Bondarco, 1990).

L. A. Chernyakhovskaya draws attention to the personnel characters of attitude to the reality of sentence content. She considers the subjective evaluation of sentences viewpoint of the speech's real level, evaluation of exactness level as the speakers' sentences to faithfulness, its evaluation as desirable or undesirable (Chernyakhovskaya, 1986).

As to our opinion, looking through the two types and separating them into two parts are more suitable. Firstly, it is very difficult to deny the objective modality in the text, in the sentence and in the speech. For example, "Each of sentence is an affirmative sentence", here not any subjective relations about the sentence. Here is given the objective information by the generalization and typicality ways. Beside this, objective modality conception is very close with the temporality categories and differentiating with definite and indefinite signs if time is impossible in subjective modality. V. L. Naer notes that "exactly the relevant with the purposes and duties of interpretation of the text in subjective modality" (Naer, 2001).

When we talk about the category of modality, we remember the sentences of I. R. Galperin, the English specialist who said "Generally, the specialists are afraid of giving terms to the same category, it seems as their adoption as realities and limitation of showing the modality forms make them be afraid (Con Layonz, RendolfKverk)" (Galperin, 1981).

It is real that we have not noticed modality terms in works of English grammarians'. In the scientific literary of America we see the identification of the verbal forms and modality categories. Thus, E. Hempin based on E. Sepire in the linguistic terminological dictionary writes: "Traditionally the modality is grammatical categories as known forms (or the conceptions belonging to them), under the "modality" I see and understand more formal expression of them than the connotations of negotiation and hesitation." (Hump, 1964) 


\section{Conclusion and Result}

Thus, though there are enough who have been trying to clarify the modality conception in the seriously scientific research works, there is not any unit view yet. Many scientists have the same opinion, and when they use the term of modality they mean sentences of speakers and their real attitude to realities. But the perfection forms of the same attitude and expression means is very different, and it is impossible to system unit inclination and make groups and come to common conclusions. Besides, the special peculiarities of each language and national specialities of non-verbal means make the same inclination impossible.

\section{Reference}

Akhmanova, O. S. (1969). Dictionary of linguistic terms (2nd ed.). Moscow: Soviet Encyclopedia.

Arbuzov, E. (2001). Pragmatic particular connotation in the organization of the text: On a material of English., Moscow: Dis. FSC.

Aristov, S. A. (1998). Non-verbal communication components. Tverskaya linguistic Meridian. Tiberias State University.

Bellert, I. (1978). A condition for the connectedness of the text. New in Foreign Linguistics, 8.

Bogdanov, V. (1987). Function of verbal and nonverbal components in speech communication. Linguistic communication: the units and regulative. Kalinin State University.

Bondarko, A. V. (1990). The theory of functional grammar.

Chernyakhovskaya, L. (1986). Modality as a text category. Questions semantics of linguistic units. Ufa: Bashkir State University.

Galperin, I. R. (1981a). Text as an object of linguistic study (5th ed.). Moscow: Science.

Galperin, I. R. (1981b). The style of the English language. Moscow: High School.

Hump E. (1964). Dictionary of American linguistic terminology. Moscow: Progress.

Huseinzadeh, M, (1973). Modern English. Baku: Education.

Kazımov, G. (n.d.). Sentence. Retrieved from http://www.qkazimov.gen.az/arxiv/15.htm/

Kolshansky, G. V. (1983). On the mechanism of generation language text. Questions of Linguistics, 3.

Linguistic Encyclopedic Dictionary. (1990). Moscow: Soviet Encyclopedia.

Lyapon M. (1971). On the question of language modality specificity. Proceedings of the Academy of Sciences of the USSR.

Maidanova, L. (1987). The structure and composition of newspaper text. Expressive means of letters. Krasnoyarsk.

Mamedov, A. (2008). Modern problems of linguistics. Baku: AUL Publishing House.

Miloserdova, E. V. (1991). Semantics and Pragmatics of modality. Voronezh: Publishing House of VSU.

Moskalskaya, O. I. (1981). The grammar of the text. Moscow: High School.

Naer, V. L. (2001). Lectures on the theoretical foundations of interpretation of the text. Moscow: Moscow State Linguistic University.

Petrunicheva, N. S. (1990). Connotation as a means of expressing subjective modality. Subjective modality: Collection of scientific works. Tyumen: Tyumen State University.

Rudnev, V. (1997). Dictionary culture of the twentieth century. Moscow: Agraf.

Russian grammar. (1980). V.2. Syntax. Moscow: Science.

Russian language. (1979). Encyclopedia. Moscow: Soviet Encyclopedia.

Torsueva, I. (1975). Functional theory of intonation. Moscow: Sciences.

Valgin, N. S. (n.d.). Author's modality. Image of the author. Theory of the text. Retrieved from http://www.M-edu.ru/x-books/xbook029/01/index.html?part-012.htm/

Vinogradov, V. (1975). Studies on Russian grammar. Moscow: Science.

http://teneta.rinet.ru/rus/me/milevskat-discourseandtextdfn.htm

http://www.nsu.ru/psych/ internet/bits/vandijk2.htm 


\section{Copyrights}

Copyright for this article is retained by the author(s), with first publication rights granted to the journal.

This is an open-access article distributed under the terms and conditions of the Creative Commons Attribution license (http://creativecommons.org/licenses/by/3.0/). 